\title{
An Assessment of Specialist Physician Referral Practices for Long-Term Cardiovascular Risk Reduction in the Community: Are We Using Our Available Resources?
}

By Kathryn Watson MD, Janeve Desy MD, T. Lee-Ann Hawkins MD, Eliana Castillo MD, Amy Metcalfe PhD

\begin{abstract}
About the Authors
Kathryn Watson, Janeve Desy, T. Lee-Ann Hawkins, Eliana Castillo, Amy Metcalfe, are all with the Department of Medicine, University of Calgary, T. Lee-Ann Hawkins, Eliana Castillo, and Amy Metcalfe, are also with the Department of Obstetrics and Gynecology, University of Calgary, and Amy Metcalfe is with the Department of Community Health Sciences, University of Calgary.
\end{abstract}

Corresponding Author amy.metcalfe@ahs.ca

Submitted: June 16, 2017. Accepted July 27, 2017. Published December 29, 2017.

\begin{abstract}
Background: Our aim was to evaluate specialist physicians' referral patterns for cardiovascular risk reduction (CRR) while identifying existing CRR programs in a large Canadian city.

Methods: This was a cross-sectional study involving an electronic survey of cardiologists and internists in Calgary, Alberta, to assess CRR referral patterns. A concurrent online search for programs addressing CRR was undertaken.

Results: Twenty-four CRR programs were identified. Nine (37.5\%, 95\% CI: 21.2-57.2) required physician referral. Half (50.0\%, 95\% CI: 31.4-68.6) had no direct patient cost.

A majority of surveyed physicians estimated that more than half of their patients have at least one modifiable risk factor. However, 75.0\% (95\% CI: 61.2-85.1) had referred less than half of these patients for CRR.

Conclusion: Our study demonstrates a gap in specialist physician referral practices for CRR. Patients with modifiable risk factors may not be accessing valuable CRR resources.

\section{Résumé}

Contexte : Notre but consistait à évaluer les habitudes d’orientation des médecins spécialistes en ce qui a trait à la réduction du risque cardiovasculaire (RRCV) et à recenser les programmes de RRCV présents à l'intérieur d'une grande ville canadienne.

Méthodologie : Une étude de prévalence a été menée par sondage électronique auprès des cardiologues et des internistes de la ville de Calgary, Alberta, dans le but d'évaluer les habitudes dorientation en ce qui a trait à la réduction du risque cardiovasculaire (RRCV). Parallèlement, une recherche sur les programmes de RRCV a été entreprise, en ligne également.

Résultats : On a répertorié 24 programmes de RRCV. Neuf (37,5\%; IC de $95 \%$ : 21,2-57,2) nécessitent que le patient soit recommandé par un médecin. La moitié (50,0 \%; IC de $95 \%$ : 31,4-68,6) n’engendre aucun coût direct pour le patient.
\end{abstract}


La plupart des médecins interrogés évaluent que plus de la moitié de leurs patients présente au moins un facteur de risque modifiable. Cependant, 75,0 \% (IC de $95 \%: 61,2-85,1$ ) ont orienté moins de la moitié de ces patients vers un programme de RRCV.

Conclusion : Notre étude montre qu'il y a une lacune dans les pratiques dorientation des médecins spécialistes relativement aux programmes de RRCV. Ainsi, des patients ayant des facteurs de risque modifiables n’ont pas accès à des ressources précieuses en matière de RRCV.

Cardiovascular disease (CVD) is the leading cause of morbidity and the second leading cause of mortality in Canada ${ }^{1,2}$ It is responsible for approximately one death every 7 minutes, ${ }^{2}$ causing $20 \%$ of deaths in Canada per year ${ }^{1}$. CVD places a significant burden on individuals, their families and the health care system, with an annual cost of approximately $\$ 20$ billion per year. ${ }^{3}$ Currently, there are an estimated 1.3 million Canadians living with CVD. ${ }^{2}$ The factors that predispose individuals to the development of CVD can be divided into modifiable and non-modifiable risk factors. It is well established that decreasing the number and severity of modifiable risk factors (MRF) can have a large impact on primary prevention of $\mathrm{CVD},{ }^{2,4-7}$ as well as secondary prevention and mitigation of established CVD. ${ }^{8-10}$ Modifiable risk factors include: obesity, diabetes mellitus, hypertension, smoking, dyslipidemia, obstructive sleep apnea, lack of exercise and stress. ${ }^{2,6,11}$ Cardiovascular risk reduction (CRR) programs address modifiable risk factors and have demonstrated appreciable reductions in morbidity and mortality from CVD. ${ }^{4,6,11-15}$

Unfortunately, Canadian physicians have limited time to counsel their patients regarding CRR. ${ }^{16}$ The focus of doctor-patient interactions tends to prioritize diagnosis and management of established medical disease. In this time constrained environment, less time is available for addressing MRF. Furthermore, many physicians are unaware of community resources available to their patients and therefore may miss the opportunity to refer those in need. It is essential that physicians whose patients have the highest burden of MRF are aware of available programs for CRR in their communities to facilitate referral.

The objective of our study was to identify the discrepancy between specialist physicians' referral patterns for CRR programs and the existing programs that are available to patients in a large Canadian city in order to establish areas for future quality improvement.

\section{Methods}

This was a cross-sectional study that involved an electronic survey of all cardiologists and internists in Calgary, Alberta, Canada to assess their CRR referral practices. A community audit of all available programs addressing CRR in Calgary, Alberta was also undertaken such that a comparison between specialist referral practices and available programs could be made.
An electronic survey was distributed requesting basic demographic data as well as referral patterns to CRR programs (Figure 1). Contact information for all academic-affiliated cardiologists and internists in Calgary was identified using divisional email lists. The survey was sent to 137 specialists using these institutional email addresses.

Concurrently, an online search was undertaken on May $3^{\text {rd }}$, 2016 using Google, Alberta Health Services and Calgary-area primary care network websites to identify all outpatient programs in Calgary, Alberta targeting CRR. Key words included "Calgary" AND ("coronary artery disease, cardiovascular disease, smoking, diet, obesity, overweight, high BMI, inactivity, hypertension, high blood pressure, cholesterol, dyslipidemia, OR diabetes") AND ("risk reduction, risk mediation, OR program"). Combinations of keywords were searched and the first 10 pages of each strategy were reviewed until saturation was reached. All identified programs were screened for inclusion into the study. Eligibility for inclusion required program location within Calgary and that at least one cardiovascular risk factor was targeted. Programs were excluded if they did not require in-person attendance. Additionally, all private for-profit businesses, including private gyms, private personal trainers, private weight management centres and pharmacy-based programs were excluded.

Statistical analysis of survey results and the community audit data involved calculation of proportions and 95\% confidence intervals and included chi-square and ANOVA testing. Data analysis was conducted using Microsoft Excel and Stata SE version 14.

\section{Results}

We encountered 24 programs targeting CRR in Calgary that met our inclusion and exclusion criteria (Table 1). Of these programs, 20 addressed weight loss (83.3\%, 95\% CI: 61.1-94.0), 17 offered nutritional counselling (70.8\%, 95\% CI: 48.5-86.2), 14 dealt with smoking cessation (58.3\%, 95\% CI: 36.8-77.1) and 14 counselled patients on diabetes management (58.3\%, 95\% CI: 36.8-77.1). A further 12 programs managed hypertension (50.0\%; 95\% CI: 29.7-70.3), 12 addressed lipid control (50.0\%, 95\% CI: 29.7-70.3), and 11 offered exercise programs (45.8\%, 95\% CI: 26.3-66.8). Five programs offered resources for obstructive sleep apnea $(20.8 \%, 95 \%$ CI: 8.3-43.2). (Table 2) 

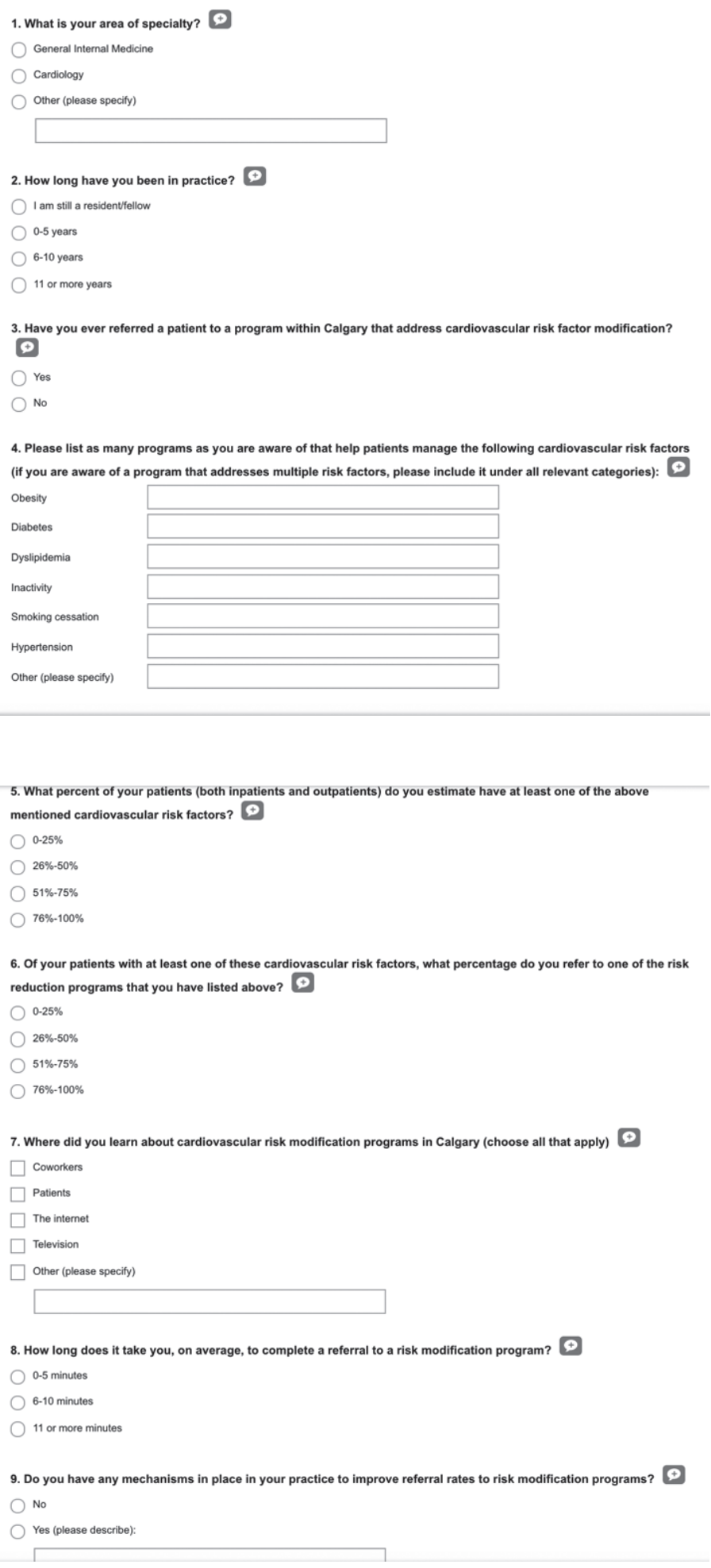

Figure 1. Electronic survey of cardiac risk reduction referral practices.

Overall, 18 programs (75.0\%, 95\% CI: 55.1-88.0) addressed three or more risk factors, and 9 programs $(37.5 \%, 95 \% \mathrm{CI}$ : 21.2-57.2) required physician referral. Half of the programs (50.0\%, 95\% CI: 31.4-68.6) had no associated cost to the patient, and a further third (29.2\%, 95\% CI: 14.9-49.1) had a direct patient cost of less than $\$ 100$ (Table 2).

Overall, 48 out of 137 (35.0\%, 95\% CI: 27.6 - 43.3) physicians surveyed responded to the cardiovascular risk factor modification questionnaire (Figure 1). 83.3\% of respondents (40/48, 95\% CI: 70.4-91.3) estimated that more than half of their patients had at least one modifiable cardiovascular risk factor. Three quarters of physicians (75.0\%, 95\% CI: 61.2-85.1) reported that they refer less than half of their eligible patients to a program that addresses CRR, despite the availability of these programs. Respondents reported that they lacked resources about available programs and $83.3 \%$ of physicians surveyed (40/48; 95\% CI: 70.4-91.3) reported that they did not have mechanisms in place to improve referral rates to these programs.

\section{Discussion}

The objective of our study was to establish whether a discrepancy exists between cardiologist and internist referral practices for CRR and the number of programs available in the community. When the results of our community audit were compared to physician responses regarding available CRR programs, there was a noticeable inconsistency between the number of programs quoted by survey participants, and those identified by the study authors. It is evident that many physicians are not aware of the plethora of community CRR programs available to their patients and are not routinely referring patients to these programs. As $37.4 \%$ of the identified programs require physician referral, the lack of awareness and low referral rate are undoubtedly limiting patient access to important resources. To our knowledge this is the first study of its kind to demonstrate a substantial gap between physician referral practices compared to the availability of CRR programs in a large Canadian city.

The long-term economic benefit of addressing CRR in population-based studies is well-established $4,5,17,18$. The Public Health Agency of Canada's planned spending for 201617 to address chronic non-communicable diseases was just under $\$ 60$ million. This includes funding for population health approaches that address common risk and protective factors for chronic diseases, including CRR strategies.19,20 Similarly, the 2017 Alberta health-spending budget allocated $\$ 700,000$ towards funding population and public health programs to confront the issue of an aging population with a high burden of chronic disease.21 Given that CVD is our most prevalent chronic disease, costing the Canadian health care system $\$ 20$ billion per year,3 these federal and provincial expenditures are relatively minimal and carry significant potential to improve the quality of life of those with CVD, while slowly decreasing the economic impact of this disease over time. However, for this to be the case patients with cardiovascular risk factors need to be accessing 
Table 1. Community-based Cardiovascular Risk Reduction Programs in Calgary, Alberta

\begin{tabular}{|c|c|c|c|c|}
\hline \multirow{2}{*}{ Name of Program } & \multirow{2}{*}{$\begin{array}{l}\text { \# CRR services } \\
\text { offered }\end{array}$} & \multirow{2}{*}{$\begin{array}{l}\text { Physician Referral } \\
\text { Required }\end{array}$} & \multicolumn{2}{|c|}{ Cost to Patient* } \\
\hline & & & Free & $<100$ \\
\hline Total Cardiology & 6 & + & + & + \\
\hline Alberta Healthy Living Program & 7 & - & + & - \\
\hline Calgary Weight Management Center & 5 & + & + & + \\
\hline C-endo & 5 & + & + & + \\
\hline LMC & 5 & + & + & + \\
\hline C-Era & 7 & + & + & + \\
\hline Trym gym & 3 & - & - & - \\
\hline Alberta Quits & 1 & - & + & - \\
\hline Sleep Disorders clinic & 3 & + & + & + \\
\hline Complex Chronic Disease Management Clinic & 7 & + & + & - \\
\hline Endocrinology \& Metabolism Program & 5 & + & + & - \\
\hline Mosaic Primary Care Network & 8 & + & + & - \\
\hline Prescription to Get Active Program & 2 & + & + & - \\
\hline Calgary Foothills Primary Care Network & 4 & - & + & - \\
\hline Calgary West Primary Care Network & 5 & + & + & - \\
\hline East Calgary Family Care Clinic & 2 & - & + & - \\
\hline Women's Health Resources & 2 & - & + & - \\
\hline Heart Fit Clinic & 8 & - & - & - \\
\hline Cardio Metabolic Risk Reduction Program & 6 & - & - & - \\
\hline Calgary Foothills Tobacco Cessation Workshop & 1 & + & + & - \\
\hline Run to Quit & 3 & - & - & + \\
\hline South Health Campus Wellness Centre & 6 & - & + & - \\
\hline CUPS Diabetes Education Program & 1 & - & + & - \\
\hline Diabetes Calgary Care Centre & 3 & - & + & + \\
\hline
\end{tabular}

* Some programs offered additional services for less than $\$ 100$, beyond those offered for free.

CRR programs. As we have demonstrated, a substantial amount of this responsibility lies in the hands of specialist physicians and remains contingent on their referral practices, otherwise we are wasting this valuable resource.
Given the high prevalence and substantial impact of CVD on quality of life, this study should serve as a call to action for other centres to survey their own referral practices and implement strategies to improve patient access to these potentially life-saving 
Table 2. Number and Percentage of Community Programs Addressing Modifiable Cardiovascular Risk Factors

Modifiable Risk Factor (MRF)
Number of Programs Addressing MRF

\begin{tabular}{|l|c|}
\hline Weight loss & $20(83.3,95 \% \mathrm{Cl}: 61.1-94.0)$ \\
\hline Nutrition & $17(70.8,95 \% \mathrm{Cl}: 48.5-86.2)$ \\
\hline Smoking & $14(58.3,95 \% \mathrm{Cl}: 36.8-77.1)$ \\
\hline Diabetes & $14(58.3,95 \% \mathrm{Cl}: 36.8-77.1)$ \\
\hline Hypertension & $12(50.0,95 \% \mathrm{Cl}: 29.7-70.3)$ \\
\hline Dyslipidemia & $12(50.0,95 \% \mathrm{Cl}: 29.7-70.3)$ \\
\hline Exercise Programs & $11(45.8,95 \% \mathrm{Cl}: 26.3-66.8)$ \\
\hline Sleep Apnea & $5(20.8,95 \% \mathrm{Cl}: 8.3-43.2)$ \\
\hline
\end{tabular}

programs. We propose that a possible method to decrease this gap could be to create and distribute a list of all available resources to all cardiologist and internist offices. Ideally, this document would include all available CRR programs, with referral instructions and contact information. Additionally, an online version of the brochure could be uploaded to the Regional Health Services website for ease of access by any local physician, expanding the use of this information to include primary care providers as well. Lastly, development of a brief screening tool to be used at each office visit would insure that patients are appropriately identified for CRR

Limitations of this study include the use of a surrogate marker for physician referral practices (self-reporting) as opposed to actual referral rates. Unfortunately, referrals to CRR programs are not currently tracked in our health care system, and therefore, identification of true referral rates would be very difficult to determine. Further limitations include the low survey response rate (35.0\%); however, the reported average physician response rate for online surveys is approximately $30 \%, 22,23$ and there is no consensus or evidence-based lowest recommended response rate required to minimize non-response bias.22 Study strengths include development of a detailed list of CRR programs (Table 1) as well as identification of low referral rates for CRR, which will further inform efforts to mitigate this issue.

\section{Funding Sources}

Amy Metcalfe is supported by a New Investigator Award from the Canadian Institutes of Health Research.

\section{Disclosures}

The authors have no disclosures.

\section{References}

1. Statistics Canada. The 10 leading causes of death in canada, 2011. 2011 2015-11-27 [cited 2016; Available at: http://www.statcan.gc.ca/pub/82625-x/2014001/article/11896-eng.htm.

2. American Heart Association Writing Group. Heart disease and stroke statistics-2016 update: a report from the American Heart Association. Circulation 2016;133(4):e38-360.

3. Tarride JE, et al. A review of the cost of cardiovascular disease. Can J Cardiol 2009;25(6):e195-202.

4. Al-Omran M. Knowledge and attitude of physicians in a major teaching hospital towards atherosclerotic risk reduction therapy in patients with peripheral arterial disease. Vasc Health Risk Manag 2007;3(6):1019-27.

5. Artinian NT, et al., Interventions to promote physical activity and dietary lifestyle changes for cardiovascular risk factor reduction in adults: a scientific statement from the American Heart Association. Circulation 2010;122(4):406-41.

6. Eckel RH, et al. $2013 \mathrm{AHA} / \mathrm{ACC}$ guideline on lifestyle management to reduce cardiovascular risk: a report of the American College of Cardiology/ American Heart Association Task Force on Practice Guidelines. J Am Coll Cardiol 2014;63(25 Pt B):2960-84.

7. Mann KV and Putnam RW. Physicians' perceptions of their role in cardiovascular risk reduction. Prev Med 1989:18(1):45-58.

8. Smith SC, et al. AHA/ACCF Secondary prevention and risk reduction therapy for patients with coronary and other atherosclerotic vascular disease: 2011 update: a guideline from the American Heart Association and American College of Cardiology Foundation. Circulation 2011;124(22):2458-73.

9. Avanzini F, et al. Improving cardiovascular prevention in general practice: Results of a comprehensive personalized strategy in subjects at high risk. Eur J Prev Cardiol 2016;23(9):947-55.

10. Notara V, Panagiotakos DB, and Pitsavos CE. Secondary prevention of acute coronary syndrome. Socio-economic and lifestyle determinants: a literature review. Cent Eur J Public Health 2014;22(3):175-82.

11. Pennant $\mathrm{M}$, et al. Community programs for the prevention of cardiovascular disease: a systematic review. Am J Epidemiol 2010;172(5):501-16.

12. Castaldo J, et al. Physician attitudes regarding cardiovascular risk reduction: the gaps between clinical importance, knowledge, and effectiveness. Dis Manage 2005;8(2):93-104.

13. Duncan A, Natarajan MK, and Schwalm JD. Assessing physician barriers to cardiac rehabilitation referral rates in a tertiary teaching centre. Can J Gen Int Med 2016;11(1):14-18.

14. Fischer JP, Automatic referral to cardiac rehabilitation. J Cardiovasc Nurs 2008;23(6):474-9. 


\section{CSIM Mission Statement}

\section{Mission Statement}

The CSIM is a non-profit professional society that promotes the health and well being of Canadian patients, their communities, and their health care systems. We seek to foster leadership and excellence in the practice of General Internal Medicine (GIM) through research, education, and advocacy for health promotion and disease management. rehabilitation enrollment: a prospective multilevel study. Eur J Cardiovasc Prev Rehabil 2008;15(5):548-56.

16. Dugdale DC, Epstein R, and Pantilat SZ. Time and the patient-physician relationship. J Gen Intern Med 1999;14 Suppl 1:S34-40.

17. Lytvyak, E., et al., Impact of a 3-year multi-centre community-based intervention on risk factors for chronic disease and obesity among freeliving adults: the Healthy Alberta Communities study. BMC Public Health 2016;16:344.

18. Barton P, et al. Effectiveness and cost effectiveness of cardiovascular disease prevention in whole populations: modelling study. BMJ 2011:343.

19. Philpott JP. Public Health Agency of Canada 2016-17: Report on plans and priorities. 2016 [cited 2017 April 2]; Available at: https://www.canada.ca/en/ public-health/corporate/transparency/corporate-management-reporting/ reports-plans-priorities/2016-2017-report-plans-priorities.html - s2_1.2.

20. Hoffman S Alberta Health Business Plan 2017-2020. 2017.

21. Government of Alberta. Health funding: Budget 2017. 2017 [cited 2017 April 2]; Available at: http://www.health.alberta.ca/about/health-funding.html.

22. Sheehan KB. E-mail survey response rates: a review. J Comp-Mediate Communicat 2001; DOI: 10.1111/j.1083-6101.2001.tb00117.x

23. University of Texas. Survey response rates. [cited 2017 January 31]; Available at: https://facultyinnovate.utexas.edu/sites/default/files/response_rates.pdf.

\section{Vision}

We believe that General Internal Medicine in Canada plays a central role in the training of current and future clinicians, in clinical research, in patient care, in health promotion, and in health advocacy; and that it unites a body of knowledge, values, and principles of care that lay the foundation for excellence in the Canadian health care system.

\section{Values}

We embrace the ethical and professional standards that are common to all healing professions, as well as the specific values of generalism, teamwork, competency-based training, life-long learning, evidence-based medicine, holism, and humane, patient-centered care.

\section{Mission}

La Société canadienne de médecine interne (SCMI) est une association professionnelle sans but lucratif qui entend promouvoir la santé et le bienêtre des patients, des collectivités et des systèmes de santé canadiens. Elle souhaite également promouvoir le leadership et l'excellence dans l'exercice de la médecine interne générale en favorisant la recherche, léducation, la promotion de la santé et la gestion des soins thérapeutiques.

\section{Vision}

La Société a l'intime conviction que la médecine interne générale occupe une place centrale dans la formation des cliniciens aujourd'hui et à l'avenir, dans la recherche clinique, dans la prestation des soins et des services de santé et dans la promotion de la santé, et que la discipline se fonde sur un savoir, des valeurs et des principes thérapeutiques essentiels à la poursuite de l'excellence dans le système de santé canadien.

\section{Valeurs}

La Société fait sienne les normes éthiques et professionnelles communes aux professions de la santé ainsi que les valeurs particulières du généralisme, du travail d'équipe, de la formation axée sur les compétences, de léducation permanente, de la médecine factuelle, de l'holisme et des soins et des services de santé humains, centrés sur le patient.

\section{CSIM Continuing Professional Development Mission Statement}

Our ultimate goal is to go beyond the simple transmission of information. Our goal is to make a lasting impact on the knowledge, skills and attitudes of clinicians and future clinicians; to narrow the theory to practice gap; to improve the health of our patients and of all Canadians.

\section{Mission de la SCMI sur le plan du développement professionnel continu}

Notre but ultime déborde du cadre de la simple transmission d'information. Il consiste à produire un effet durable sur le savoir, les compétences et les attitudes du médecin, à combler lécart qui sépare la théorie de la pratique, à améliorer la santé de nos patients et de tous les canadiens. 